\title{
KOMUNIKASI PEMASARAN DALAM RANGKA PEMBERDAYAAN EKONOMI MASYARAKAT PETANI MENTE DESA SOKET LAOK, KABUPATEN BANGKALAN, MADURA
}

\author{
MARKETING COMMUNICATION TRAINING FOR ECONOMIC \\ EMPOWERMENT SOKET LAOK, BANGKALAN, MADURA
}

\author{
Rani Sukma Ayu Suteja ${ }^{1}$, Santi Isnaini' ${ }^{2}$, Liestianingsih Dwi Dayanti ${ }^{3}$,Yayan Sakti \\ Suryandaru ${ }^{4}$, Yuyun Wahyu Izzati Surya' ${ }^{5}$ Andria Saptyasari ${ }^{6}$, Titik Puji Rahayu ${ }^{7}$, \\ Dina Septiani $^{8}$, Nisa Kurnia Illahiati ${ }^{9}$, Angga Prawadika Aji ${ }^{10}$, Igak Satrya \\ Wibawa $^{11}$ \\ 1,2,3,4,5,6,7,8,9,10,11 Departemen Komunikasi, Fakultas Ilmu Sosial dan Ilmu Politik, \\ Universitas Airlangga Jl. Dharmawangsa Dalam Kampus B Universitas Airlangga, \\ Surabaya- 60286 \\ email: ranisukma@fisip.unair.ac.id
}

\begin{abstract}
Soket Laok is a village with population of 4173 in Kecamatan Tragah, Kabupaten Bangkalan, Madura. Soket Laok has so many potentials but still underdeveloped. The biggest potential of Soket Laok is agriculture. However, the farmers themselves do not understand how to sell their product. In addition, the lack of knowledge in the use of information and communication technology is also a big problem. Therefore, the Department of Communication FISIP UNAIR carried out a community service activity entitled Marketing Communication Training for Economic Empowerment in Soket Laok Village, Bangkalan Regency, Madura. This training increases the participants' understanding of the importance of marketing communication.
\end{abstract}

Keywords: marketing communication, cashew farmer

\section{abstrak}

Desa Soket Laok adalah desa yang berada di Kecamatan Tragah, Kabupaten Bangkalan Madura yang memiliki sekitar 4173 jiwa penduduk. Desa Soket Laok masih dapat dibilang daerah yang tertinggal dan belum dapat memaksimalkan potensi desa untuk kesejahteraan warganya. Potensi terbesar desa Soket Laok adalah pertanian. Akan tetapi, petaninya sendiri kurang paham bagaimana mengolah dan menjual hasil panen ke luar wilayah Soket Laok. Selain itu, kurangnya pemahaman dalam penggunaan teknologi informasi dan komunikasi juga menjadi salah satu permasalahan. Oleh karena itu, Departemen Komunikasi FISIP UNAIR melaksanakan kegiatan pengadian masyarakat berjudul Pelatihan Komunikasi Pemasaran dalam Rangka Pemberdayaan Ekonomi Masyarakat Petani Mente Desa Soket Laok, Kabupaten Bangkalan, Madura. Pelatihan ini meningkatkan pemahaman para peserta kegiatan tentang pentingnya komunikasi pemasaran

Kata Kunci: komunikasi pemasaran, petani mente

\section{PENDAHULUAN}

Desa Soket Laok adalah desa yang berada di Kecamatan Tragah, Kabupaten Bangkalan Madura yang memiliki sekitar 4173 jiwa penduduk. Desa Soket Laok merupakan desa yang memiliki area paling luas di Bangkalan Madura dan juga merupakan salah satu desa yang memiliki potensi ekonomi terbesar terutama dalam bidang pertanian. Oleh 
karena itu, sebagian besar warga desa Soket Laok adalah petani . Namun meskipun demikian, desa Soket Laok masih dapat dibilang daerah yang tertinggal dan belum dapat memaksimalkan potensi desa untuk kesejahteraan warganya (LPPM Universitas Trunojoyo, 2019).

Melihat permasalahan tersebut, pada tanggal 16 Januari 2020 lalu, Departemen Komunikasi FISIP Unair menandatangani sebuah nota kesepakatan (Memorandum of Agreement, MoA) dengan Desa Soket Laok (FISIP UNAIR, 2019). Nota kesepakatan ini adalah salah satu bentuk implementasi dari Tri Dharma Perguruan Tinggi dari Departemen Komunikasi FISIP Unair yang diorientasikan untuk mengembangkan potensi desa-desa yang ada di Jawa Timur, termasuk Desa Soket Laok. Rencananya dalam 5 (lima) tahun ke depan, kegiatan penelitian dan pengabdian masyarakat dengan pola kemitraan akan dilakukan di desa Soket Laok. Setelah penandatanganan nota kesepakatan, beberapa kali kunjungan awal pun dilakukan untuk memetakan permasalahan yang dihadapi oleh desa Soket Laok.

Setidaknya, ada beberapa permasalahan yang ditemukan. Pertama, desa Soket Laok berlokasi tidak jauh dari Surabaya, namun masih bisa dibilang desa yang tertinggal sehingga potensi desanya tidak bisa dikembangkan secara maksimal. Kedua, potensi ekonomi terbesar dari desa Soket Laok adalah mente. Meskipun demikian, petani mentenya sendiri kurang paham bagaimana mengolah dan menjual mente tersebut ke luar wilayah Soket Laok sehingga mente lebih sering dikuasai oleh pengepul yang membeli dengan harga jauh di bawah harga pasar. Ketiga, kurangnya pemahaman dalam penggunaan teknologi informasi dan komunikasi juga menjadi salah satu masalah yang krusial karena akses informasi menjadi terbatas sehingga tidak paham potensi ekonomi dari desanya sendiri. Selain itu, mereka juga tidak bisa mengomunikasikan hasil bumi terbesarnya yaitu mente ke luar wilayah Soket Laok karena tidak paham teknologi informasi dan komunikasi.

Permasalahan di atas merupakan permasalahan pelik yang memiliki urgensi untuk diselesaikan melalui program pengabdian masyarakat yang berkelanjutan. Kegiatan pengabdian masyarakat dengan pola kemitraan dilakukan untuk mengurai permasalahan yang dihadapi pemerintah dan warga Desa Soket Laok. Berkait dengan hal tersebut Departemen Komunikasi FISIP Universitas Airlangga melaksanakan kegiatan pengabdian masyarakat dengan judul "Pelatihan Komunikasi Pemasaran Dalam Rangka Pemberdayaan Ekonomi Masyarakat Petani Mente Desa Soket Laok, Kabupaten Bangkalan, Madura pada tahun 2020. Komunikasi pemasaran adalah suatu usaha komunikasi untuk menginformasikan, membujuk, dan mengingatkan konsumen baik secara langsung dan tidak langsung mengenai suatu produk (Firmansyah 2019 : 2). Dalam dunia komunikasi pemasaran, dikenal komunikasi pemasaran terpadu yaitu penggabungan dari beberapa elemen komunikasi pemasaran agar tujuan pemasaran dapat tercapai secara maksimal (Chitty et al 2011 : 3). Komunikasi pemasaran terpadu terdiri dari iklan, penjualan langsung, promosi penjualan, pemasaran digital/internet, hubungan masyarakat, dan penjualan personal (Belch et al 2018 : 16). Hal ini tidak hanya dilakukan oleh perusahaan besar saja, tapi perusahaan kecil berskala UMKM juga penting untuk menerapkan komunikasi pemasaran terpadu. Terutama di era digital ini, para pelaku UMKM dapat memaksimalkan komunikasi pemasaran terpadu menggunakan internet. Oleh karena itu, kegiatan pengabdian masyarakat ini memiliki urgensi untuk dilaksanakan. 
Rani Sukma Ayu Suteja, dkk.: Pelatihan Komunikasi Pemasaran dalam Rangka Pemberdayaan Ekonomi Masyarakat Petani Mente Desa Soket Laok, Kabupaten Bangkalan, Madura

Pengabdian masyarakat dilakukan dalam bentuk pelatihan komunikasi pemasaran menggunakan teknologi komunikasi, khususnya media sosial Facebook dan Instagram, dengan sasaran perangkat utama desa, petani mente, dan kelompok Karang Taruna Desa Soket Laok. Pada awalnya kegiatan akan dilakukan secara tatap muka secara langsung. Namun, karena adanya pandemi COVID-19, kegiatan diubah menjadi kegiatan pelatihan secara daring.

\section{METODE PENGABDIAN MASYARAKAT}

Kegiatan pengabdian masyarakat ini dilakukan dengan melalui beberapa tahapan yang terdiri dari tahap persiapan, tahap pelaksanaan, dan tahap monitoring evaluasi. Tahap persiapan yang pertama adalah pertemuan dengan mitra yakni tim Pemerintah Desa Soket Laok, Kabupaten Bangkalan, Madura. Pertemuan dilakukan untuk memetakan permasalahan Desa Soket Laok. Dalam pertemuan ini Tim Departemen Komunikasi mengumpulkan informasi mengenai permasalahan Desa Soket Laok. Informasi ini menjadi bahan untuk memetakan masalah dan menyusun skema solusi Selanjutnya, pra-survei dilakukan di lokasi sasaran Desa Soket Laok Kabupaten Bangkalan. Tim melakukan kunjungan ke lokasi sasaran bertemu dengan perangkat desa antara lain Kepala Desa Soket Laok beserta staf, Kepala Dusun, tokoh masyarakat dan karang taruna. Dalam pertemuan ini diperoleh gambaran kondisi desa dan permasalahan yang dihadapi. Kemudian, tim menyusun pemetaan masalah dan mencari solusi. Seletah melakukan pemetaan masalah, tim membuat materi pelatihan berupa modul dan video animasi tutorial berjudul "Edukasi Pemanfaatan Media Sosial untuk Komunikasi Pemasaran UMKM (Peningkatan Produktivitas Pemasaran Petani Mente Desa Soket Laok, Bangkalan, Madura)". Terakhir, tim menyusun program pelatihan komunikasi pemasaran dengan menggunakan teknologi komunikasi, khususnya media sosial Facebook dan Instagram, kepada perangkat desa, petani mente dan karang taruna melalui media internet.

Setelah tahap persiapan telah matang, berlanjut ke tahap 2 yaitu pelaksanaan kegiatan. Pada tahap ini, tim melakukan sosialisasi dan program pelatihan komunikasi pemasaran dalam rangka pemberdayaan ekonomi masyarakat petani Desa Soket Laok, Kabupaten Bangkalan, Madura, Jawa Timur dengan menggunakan aplikasi Zoom. Tahap akhir yaitu tahap monitoring evaluasi dilakukan dengan menilai beberapa hal yakni: (1) Meningkatnya pemahaman dan kesadaran perangkat desa, petani, dan anggota Karang Taruna Desa Soket Laok tentang potensi ekonomi desa serta kelebihan dan pentingnya kemampuan komunikasi pemasaran. (2) Efektifnya materi pelatihan berupa modul dan video animasi tutorial berjudul "Edukasi Pemanfaatan Media Sosial untuk Komunikasi Pemasaran UMKM (Peningkatan Produktivitas Pemasaran Petani Mente Desa Soket Laok, Bangkalan, Madura)" sebagai media pembelajaran. (3) Meningkatnya keahlian/ketrampilan perangkat desa, petani, anggota Karang Taruna Desa Soket Laok dalam menggunakan teknologi informasi dan komunikasi, khususnya media sosial Facebook dan Instagram, agar komunikasi pemasaran semakin maksimal. Setelah itu, laporan akhir dan laporan keuangan disusun sebagai bentuk pertanggungjawaban kegiatan. 


\section{HASIL DAN PEMBAHASAN}

Berdasarkan latar belakang masalah yang dipaparkan, beberapa permasalahan dari mitra diantaranya: (1) Desa Soket Laok berlokasi tidak jauh dari Surabaya, namun masih bisa dibilang desa yang tertinggal sehingga potensi desanya tidak bisa dikembangkan secara maksimal. (2) Potensi besar dari desa Soket Laok adalah mente. Meskipun demikian, petani mentenya sendiri kurang paham bagaimana mengolah dan menjual mente tersebut ke luar wilayah Soket Laok sehingga mente lebih sering dikuasai oleh pengepul yang membeli dengan harga jauh di bawah harga pasar. (3) Kurangnya pemahaman dalam penggunaan teknologi informasi dan komunikasi juga menjadi salah satu masalah yang krusial karena akses informasi menjadi terbatas sehingga tidak paham potensi ekonomi dari desanya sendiri. Selain itu, mereka juga tidak bisa mengomunikasikan hasil bumi terbesarnya yaitu mente ke luar wilayah Soket Laok karena tidak paham teknologi informasi dan komunikasi.

Berkaitan dengan hal tersebut, Departemen Komunikasi FISIP Universitas Airlangga melaksanakan kegiatan pengabdian masyarakat dengan judul "Pelatihan Komunikasi Pemasaran Dalam Rangka Pemberdayaan Ekonomi Masyarakat Petani Mente Desa Soket Laok, Kabupaten Bangkalan, Madura pada tahun 2020. Pengabdian masyarakat dilakukan dalam bentuk pelatihan komunikasi pemasaran menggunakan teknologi komunikasi, khususnya media sosial Facebook dan Instagram, dengan sasaran perangkat utama desa, petani mente, dan kelompok Karang Taruna Desa Soket Laok. Pada awalnya kegiatan akan dilakukan secara tatap muka secara langsung, namun kegiatan mengalami hambatan karena adanya pandemi COVID-19.

Untuk mengatasi permasalahan tersebut, tim pengabdian masyarakat Departemen Komunikasi membuat materi pelatihan berupa modul dan video animasi tutorial berjudul "Edukasi Pemanfaatan Media Sosial untuk Komunikasi Pemasaran UMKM (Peningkatan Produktivitas Pemasaran Petani Mente Desa Soket Laok, Bangkalan, Madura)". Materi pelatihan berupa modul dan video animasi tutorial tersebut di atas akan disosialisasikan dalam sebuah program pelatihan komunikasi pemasaran dalam rangka pemberdayaan ekonomi masyarakat petani mente desa Soket Laok, Kabupaten Bangkalan, Madura.

Pelatihan ini dilakukan secara daring pada tanggal 13 November 2020 dengan sasaran perangkat desa, petani mente dan karang taruna Desa Soket Laok, Bangkalan, Madura. Pelatihan dilakukan untuk mengembangkan kemampuan perangkat desa, petani mente, dan karang taruna dalam melakukan komunikasi pemasaran produknya dengan menggunakan teknologi komunikasi dan informasi, khususnya media sosial Facebook dan Instagram. Pelatihan secara daring dilaksanakan dengan urutan sebagai berikut: (1) Teknik membuat narasi pemasaran digital. (2) Memotret produk menggunakan kamera telepon seluler. (3) Membuat video iklan dengan telepon seluler. (4) Memulai pemasaran digital. (5) Pemasaran digital dengan media sosial Facebook (6) Pemasaran digital dengan media sosial Instagram. Materi pelatihan akan diunggah di platform You Tube sehingga bisa diakses kapan saja dan di mana saja. Selain itu, materi pelatihan berupa video animasi tutorial juga akan diunggah di platform You Tube. 
Rani Sukma Ayu Suteja, dkk.: Pelatihan Komunikasi Pemasaran dalam Rangka Pemberdayaan Ekonomi Masyarakat Petani Mente Desa Soket Laok, Kabupaten Bangkalan, Madura

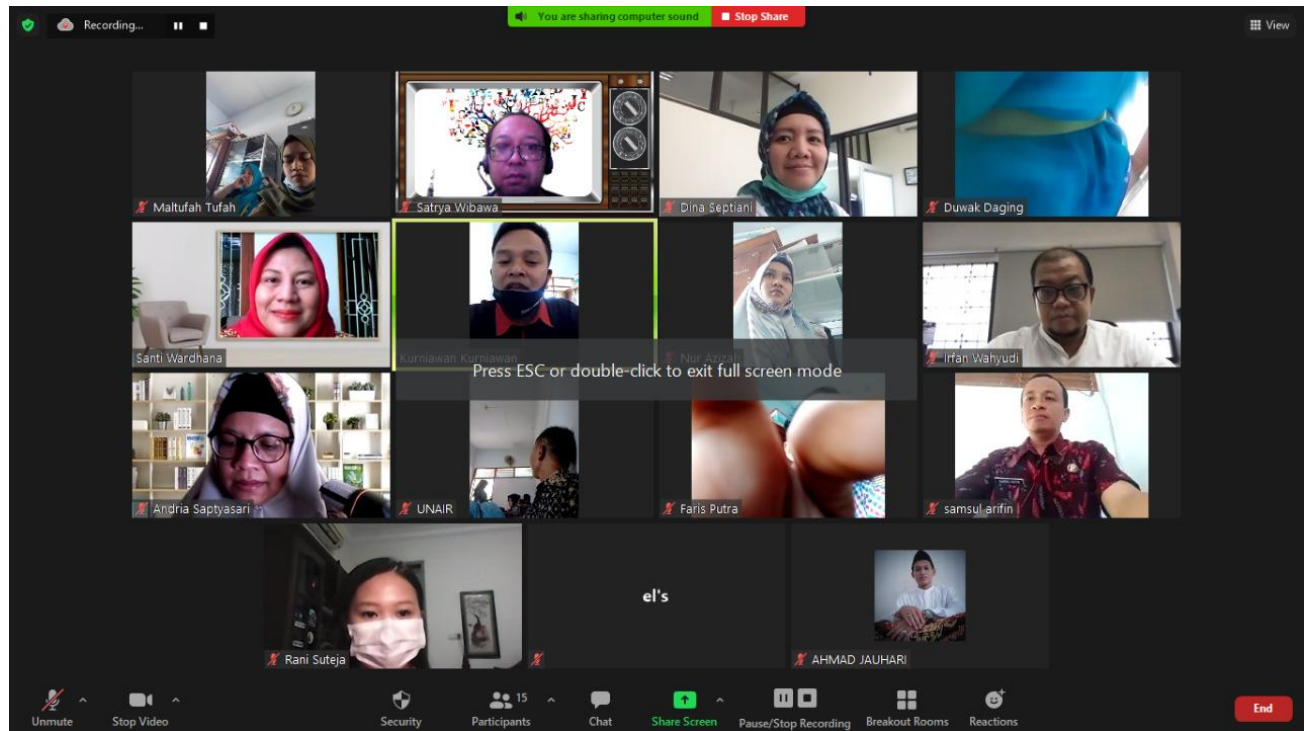

Gambar 1. Pelaksanaan pelatihan melalui Zoom

Hasil yang diharapkan dari kegiatan pembuatan modul, video animasi tutorial, dan pelatihan tersebut adalah meningkatnya pemahaman akan pentingnya sinergi dari seluruh warga untuk memaksimalkan potensi ekonomi desa, dengan memanfaatkan kemampuan komunikasi pemasaran. Manfaat lainnya adalah warga desa dapat mengembangkan kemampuan dalam menggunakan teknologi informasi dan komunikasi agar komunikasi pemasaran semakin maksimal. Dengan demikian, pemberdayaan ekonomi warga desa Soket Laok, Kabupaten Bangkalan, Madura dapat berlangsung dengan lebih baik dan mengalami peningkatan di masa mendatang.

\section{KESIMPULAN DAN SARAN}

Kegiatan pengabdian masyarakat dilaksanakan berdasarkan hasil pra-survei Desa Soket Laok, Kecamatan Tragah, Kabupaten Bangkalan Madura. Desa Soket Laok tersebut memiliki potensi besar yaitu mente. Meskipun demikian, petani mentenya sendiri kurang paham bagaimana mengolah dan menjual mente tersebut ke luar wilayah Soket Laok sehingga mente lebih sering dikuasai oleh pengepul yang membeli dengan harga jauh di bawah harga pasar. Kurangnya pemahaman dan keterampilan dalam penggunaan teknologi informasi dan komunikasi membuat para petani mente ini juga tidak bisa mengomunikasikan produknya ke luar wilayah Soket Laok. Pelatihan ini meningkatkan pengetahuan mengenai komunikasi pemasaran bagi para petani desa Soket Laok.

Pandemi COVID-19 mengubah rancangan kegiatan pengabdian kepada masyarakat ini. Pada awalnya pendampingan akan dilaksanakan secara langsung kepada perangkat desa, petani, dan Karang Taruna, namun karena adanya pandemi, kegiatan dialihkan secara daring. Oleh karena itu, saran yang dapat kami berikan adalah pelatihan perlu dilakukan secara two step flow (dua langkah) yaitu memberikan pelatihan kepada mereka memiliki kapabilitas, akses dan perangkat. Selanjutnya, mereka yang telah mendapat pelatihan bisa menyampaikan ilmu yang didapat kepada khalayak yang lebih luas. Bentuk pelatihan ini juga dikenal dengan istilah Training of Trainers (TOT) atau Pelatihan untuk Pelatih. 


\section{DAFTAR PUSTAKA}

Belch, GE, Belch, MA. 2018. Advertising \& Promotion: an Integrated Marketing Communications Perspective, Eleventh Edition. USA: MCGraw-Hill Production

Chitty, W, Barker, N, Valos, M, Shimp, TA. 2011. Intergrated Marketing Communication. Boston: Cengage Learning.

Firmansyah, A. 2019. Komunikasi Pemasaran, Pasuruan: Penerbit Qiara Media

LPPM Universitas Trunojoyo. 2019. Sejarah Soket Laok. Diakses melalui http://soketlaok.blogdesa.net/p/sejarah.html pada tanggal 19 Maret 2020

FISIP UNAIR, 2020. Aktualisasikan Pengabdian Masyarakat, Fisip Unair Tandatangani Memorandum of Agreement (Moa) Desa Binaan dengan Desa Soket Lao. Diakses melaluihttp://fisip.unair.ac.id/kerjasama/read/1259/aktualisasikan-pengabdianmasyarakat-fisip-unair-tandatangani-memorandum-of-agreement-moa-desabinaan-dengan-desa-soket-laok pada tanggal 19 Maret 2020 